\title{
In vivo and in vitro Volatile Constituents of the Flowers of Xylopia aromatica by HS-SPME/GC-MS
}

\author{
João G. M. Junqueira, ${ }^{\oplus a, b}$ Michelle N. G. do Nascimento, ${ }^{a, c}$ Lucas G. da Costa, ${ }^{c}$ \\ Lincoln L. Romualdo, ${ }^{a}$ Francisco W. B. de Aquino, ${ }^{b}$ Mustapha N. Abubakar, ${ }^{d}$ \\ Ana P. Terezan, ${ }^{e}$ Gustavo O. S. Cunha ${ }^{\oplus e}$ and Vanessa G. P. Severino ${ }^{\circledR} *, e$ \\ ${ }^{a}$ Instituto de Química, Universidade Federal de Catalão, 75704-020 Catalão-GO, Brazil \\ ${ }^{b}$ Departamento de Química, Universidade Federal de São Carlos, 13565-905 São Carlos-SP, Brazil \\ 'Instituto de Química, Universidade Federal de Uberlândia, 38400-902 Uberlândia-MG, Brazil \\ ${ }^{d}$ Department of Chemistry, Federal College of Education (Technical) Gusau, PMB 1088 Zamfara State, Nigeria \\ eInstituto de Química, Universidade Federal de Goiás, 74690-900 Goiânia-GO, Brazil
}

\begin{abstract}
Xylopia aromatica (Lam.) Mart. (Annonaceae) is a typical species from the Brazilian cerrado that presents medicinal properties. The plant is distinguished by its large white flowers which produce a pleasant fragrance. $X$. aromatica is characterized by a wide range of medicinal application. These characteristics have motivated us to investigate the flowers volatile organic compounds (VOCs) via in vivo and in vitro protocols by a headspace solid-phase microextraction (HS-SPME) technique combined with gas chromatography-mass spectrometry (HS-SPME/GC-MS). Four different fibers, extraction times and temperatures were the parameters changed to lead to the maximum profiling of the volatile constituents. Data were analyzed using principal component analysis (PCA). A total of 77 VOCs were extracted from the floral scent, with 52 and 68 extracted from in vivo and in vitro sampling, respectively, of which 48 were reported for the first time in the literature as volatile constituents from $X$. aromatica flowers. The extraction and identification of VOCs were successfully performed through HS-SPME/GC-MS. The PCA data allowed the identification of parameters that led to the maximum number of VOCs, which were polyacrylate (PA) and carboxen/polydimethylsiloxane (CAR/PDMS) fibers, 60 min extraction time and temperature of $29.0^{\circ} \mathrm{C}$. Among the volatile constituents identified, sesquiterpenes predominated, comprising about $61.04 \%$.
\end{abstract}

Keywords: Xylopia aromatica, in vivo and in vitro sampling, HS-SPME/GC-MS, VOCs, multivariate analysis

\section{Introduction}

Annonaceae is a large family of aromatic trees, shrubs, or climbers broadly distributed in tropical and subtropical regions, and which comprises more than 130 genera and 2,300 species. ${ }^{1,2}$ With considerable economic importance, this family has species that produce edible fruits, such as custard apple (Annona squamosa L.), soursop (Annona muricata L.) and numerous odorous species. These fragrances occur mainly due to the presence of essential oils, ${ }^{3}$ which constitute one of the most important groups of raw materials for food and cosmetic industries. ${ }^{1,2}$

*e-mail: vanessapasqualotto@ufg.br
The genus Xylopia is one of the largest in this family, with approximately 160 species distributed in tropical and subtropical regions of America, Africa, Asia, and Oceania. ${ }^{2}$ $X$. aromatica (Lam.) Mart., popularly known as "pimentade-macaco" ("monkey pepper" lit. translation into English) ${ }^{3}$ is a small tree generally 4-5 m (12-15 feet) tall, commonly found in the coastal forest and cerrado of Brazil (Brazilian savanna). It is distinguished by its large white flowers that produce a pleasant fragrance. ${ }^{4}$ The chemical composition of the flowers, leaves, fruits and stem bark contain the essential oil of $X$. aromatica, ${ }^{3,5-7}$ and their pharmacological properties, which include cytotoxic, ${ }^{8}$ trypanomicidal, ${ }^{9}$ antimalarial, ${ }^{10}$ anti-obesity, ${ }^{11}$ anti-inflammatory ${ }^{8}$ and antimicrobial activities ${ }^{5}$ have all been reported. 
These remarkable characteristics, besides the wide medicinal application of the plant, prompted us to investigate the volatile organic compounds (VOCs) from its flowers by the solid-phase microextraction (SPME) technique. Nowadays, SPME combined with gas chromatography coupled to mass spectrometry (GC-MS) is a consolidated analytical approach widely used in the research of these compounds from plant materials. It is considered superior to other methods due to advantages related to the principles of green chemistry as being solvent-free, besides easy to operate and versatile. ${ }^{12-14}$ In addition, the SPME technique enables in vivo and in vitro sample collection, ${ }^{15}$ followed by the direct desorption of the analytes from the fiber inside a measuring system and detection of a large number of volatile compounds. ${ }^{12-15}$

In the previous study on the VOCs from X. aromatica, Andrade et al.,${ }^{16}$ using the SPME technique, performed an in vitro sampling of a specimen from Northern Brazil and identified limonene, $\alpha$-pinene and $\beta$-pinene as the major components. However, no in vivo work of VOCs has been reported until this moment. Thus, this work investigated four different fibers, extraction times and temperatures for maximum extraction of volatile constituents from the flowers of $X$. aromatica via in vivo and in vitro techniques. In addition, the data obtained were analyzed using a multivariate analysis technique, principal component analysis (PCA).

\section{Experimental}

\section{Plant material}

The fully developed flowers of X. aromatica were randomly collected at the Federal University of Catalão farm in the city of Catalão (Goiás state), Brazil. Access to the genetic heritage was registered at the National System of Genetic Resource Management and Associated Traditional Knowledge (SisGen) under code No. A11AE20. This species was identified, and a voucher (specimen No. 6554) was deposited at the Centro-Norte-Matogrossense herbarium, Federal University of Mato Grosso, Campus Sinop. Three flowers were used for each fiber, resulting in twelve flowers per experiment.

\section{Standard compounds and materials}

Standard compounds $R$-limonene (analytical standard), $\beta$-elemene (analytical standard), trans-caryophyllene ( $\geq 98.5 \%$ ), $\alpha$-humulene ( $\geq 96 \%$ ), tridecan-2-one (99\%), pentadecan-2-one $(\geq 98 \%)$ and $\mathrm{C}_{8}-\mathrm{C}_{30} n$-alkanes were all purchased from Sigma-Aldrich (Saint Louis, USA).
The extraction procedures for the VOCs were carried out using $20 \mathrm{~mL}$ headspace vials (Agilent, Santa Clara, USA) and $250 \mathrm{~mL}$ polypropylene vials (Plaszom, Orlenas, Brazil) with caps for in vitro and in vivo sampling, respectively. The SPME fibers coated with polydimethylsiloxane (PDMS, $100 \mu \mathrm{m})$, polyacrylate (PA, $85 \mu \mathrm{m}$ ), carboxen/polydimethylsiloxane (CAR/PDMS, $75 \mu \mathrm{m})$, divinylbenzene/carboxen/polydimethylsiloxane (DVB/CAR/PDMS, 50/30 $\mu \mathrm{m}$ ) and the manual SPME holder were acquired from Supelco ${ }^{\circledR}$ (Bellefonte, USA).

Headspace solid-phase microextraction (HS-SPME) optimization procedure

In vivo and in vitro sampling of VOCs from $X$. aromatica flowers were performed (Figure 1). For in vivo experiments, the compounds were obtained from the farm. After exposure, the fibers were transported to the laboratory in screw-capped glass tubes $(20 \times 150 \mathrm{~mm}, 30 \mathrm{~mL}$, Flinn Scientific, Batavia, USA) inside a thermal box at $10{ }^{\circ} \mathrm{C}$. For in vitro experiments, the flowers were collected, and the extraction procedures were carried out immediately on arrival in the laboratory, using a circulating air stove (Nova Ética, São Paulo, Brazil) (Figure 1). In both samplings, the fibers were placed in screw-capped glass tubes and store at $7{ }^{\circ} \mathrm{C}$ until their GC-MS analysis. The fibers were then retracted into the needle and inserted into the GC injector for $60 \mathrm{~min}$ in splitless mode. Extractions were carried out in triplicate for each fiber and one empty capped vial was used as the blank control.

\section{Gas chromatography coupled to mass spectrometry (GC-MS)}

GC-MS analyses were performed on an Agilent GC-7820A gas chromatogram system equipped with HP-5 MS fused silica capillary column (5\% phenyl and $95 \%$ methylpolysiloxane $)(30 \mathrm{~m} \times 0.25 \mathrm{~mm}$ internal diameter (i.d.) and $0.25 \mu \mathrm{m}$ film thickness) coupled to an Agilent MSD 5975 mass-selective detector (Agilent Technologies, Wilmington, USA). The system operating conditions were a programmed temperature at $60{ }^{\circ} \mathrm{C}$ for 2 min, followed by an increase of $4{ }^{\circ} \mathrm{C}$ per min until $250{ }^{\circ} \mathrm{C}$, and then being kept at this temperature for $10.5 \mathrm{~min}$, an injector temperature of $250^{\circ} \mathrm{C}$, an electron ionization (EI) mode at $70 \mathrm{eV}$. Helium was used as carrier gas at a constant flow rate of $1 \mathrm{~mL} \mathrm{~min}^{-1}$; the scan range was set at $m / z$ 45-450. The mass-selective detection (MSD) parameter source temperature was set at $230^{\circ} \mathrm{C}$, and the MS source temperature was $150{ }^{\circ} \mathrm{C}$. 


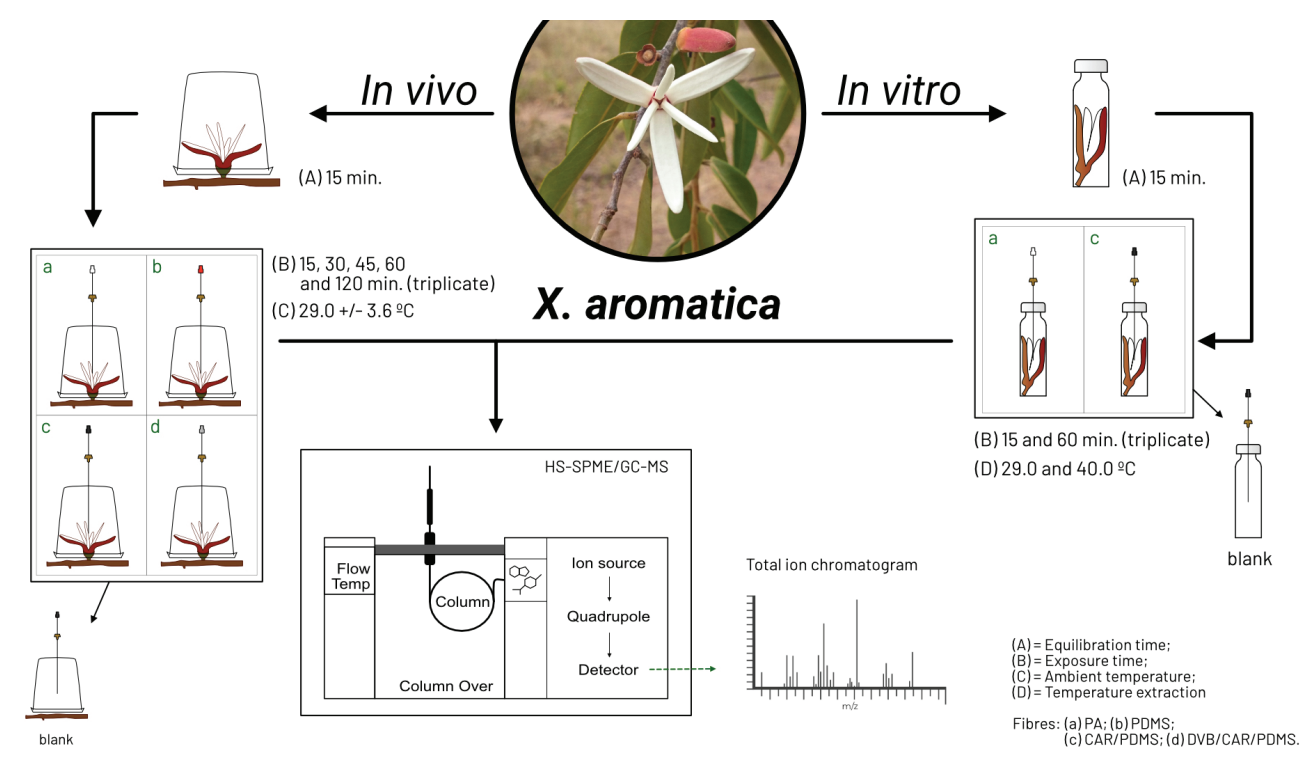

Figure 1. Steps of in vivo and in vitro experiments.

\section{VOCs identification from $X$. aromatica flowers}

The VOCs from $X$. aromatica flowers were identified based on the comparison of their mass spectra with those from the GC-MS data-base substances (NIST/EPA/NIH Mass Spectral Library, 2017). ${ }^{17}$ Additionally, the retention indices (RI) of the compounds were compared with those reported in literature databases. ${ }^{18-20}$ The RI values were determined by injecting a homologous series of $n$-alkanes $\left(\mathrm{C}_{8}-\mathrm{C}_{30}\right)$ under the same operating conditions. Before injections in the GC-MS system, blank runs (with no sample) were carried out.

\section{Multivariate analysis}

The multivariate analyses of data sets obtained from in vivo and in vitro experiments were performed independently using Pirouette ${ }^{\circledR}$ software version 4.5. ${ }^{21}$ Two distinct data matrices were created. These matrices were arbitrarily named $\mathbf{X}(\mathrm{n} \times \mathrm{m})$ for in vivo experiments and $\mathbf{Y}(\mathrm{n} \times \mathrm{m})$ for in vitro data, where $\mathrm{n}$ represents the number of chromatograms in each matrix and $\mathrm{m}$ is the 12.441 signals registered by the mass spectrometer during the $60 \mathrm{~min}$ of chromatograph run. Before the PCA, the raw data were normalized by the individual norm and mean-centered.

\section{Results and Discussion}

\section{In vivo sampling of the flower scent of $X$. aromatica}

In vivo sampling allows for obtaining a more representative floral scent metabolomic profile, since the specimen being investigated is in its habitat. In this way, this methodology eliminates the possibility of errors associated with the time taken to transport and store the sample, hence resulting in more precise, accurate and fast analytical data, besides its potential for allowing temporal and longitudinal studies. ${ }^{22-24}$

It is known that to guarantee the extraction of the largest possible number of VOCs, the variables need to be carefully investigated and optimized. Therefore, in this research, we decided to work with the fiber coating and extraction time variables simultaneously, while the extraction temperature was measured throughout all the experiments. Four different fibers (CAR/PDMS, DVB/CAR/PDMS, PA and PDMS) were evaluated during extraction times of 15 , 30, 45, 60 and $120 \mathrm{~min}$, with extraction temperatures of $29.0 \pm 3.6^{\circ} \mathrm{C}$ (Figure 2).

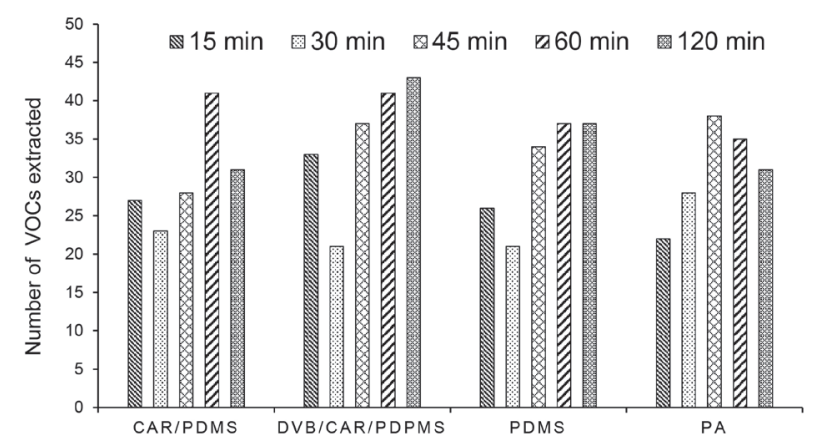

Figure 2. Effects of the extraction time and SPME fiber coating on the number of volatile compounds extracted from flowers of $X$. aromatica using in vivo experiments.

Our results showed that the times of 15,30 and $45 \mathrm{~min}$ were not enough to extract the largest number of constituents of the volatile profile. However, when a longer extraction time (120 min) was used, the desorption of the 
volatile constituents in most of the fibers resulted in a reduction in the number of VOCs. Therefore, the extraction time of 60 min was considered enough for the maximum extraction of volatile constituents from the flowers of $X$. aromatica.

As the number of compounds extracted was similar in the four different fibers, it was difficult to select a specific fiber. For this reason, to discriminate the VOCs investigated in the four fibers, the multivariate statistical method PCA was used.

\section{PCA of the in vivo sampling}

A PCA was performed to provide better visualization of VOCs data since this chemometric tool allows analyzing interrelationships between a large number of variables and explaining these variables in terms of their inherent dimensions (principal components, PCs). ${ }^{25,26}$ The results of PCA for the data set obtained in the in vivo experiments are depicted in the score plot for the first and second principal components (Figure 3). Although PC1 and PC2 explained $56.8 \%$ out of the total variation of the data set, it was not possible to observe a clear separation in the chromatographic profiles for the four fibers. However, remarkable segregation of data in two groups was clearly perceived along the $\mathrm{PC} 1$ axis. The first group is composed of data from extractions performed using the PA and PDMS fibers, which were strongly correlated with variables (VOCs) that exhibit negative loadings for PC1. The second group is composed of data from extractions performed with CAR/PDMS and DVB/CAR/PDMS fibers, which were highly correlated with variables (VOCs) that exhibit positive loadings for PC1.

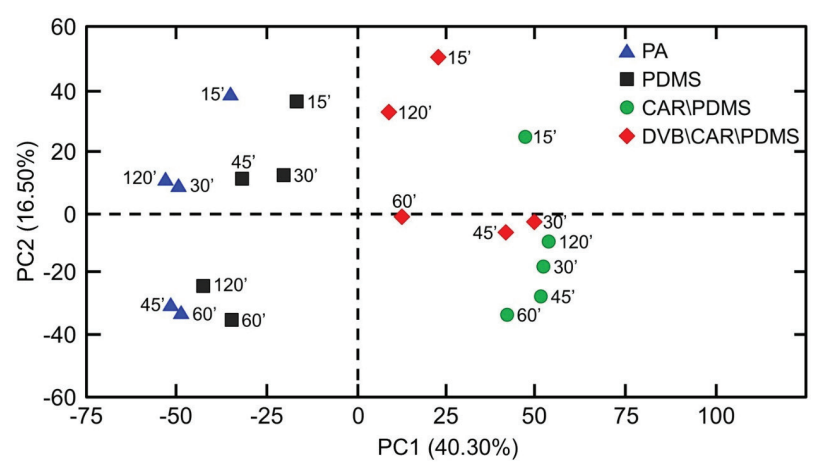

Figure 3. Scores plot of PCA for chromatograms obtained from in vivo experiments.

Beyond the molecular weight (MW) of the analytes extracted, the most probable reason to explain this separation of data can be the polarity of the VOCs associated with each fiber.
The extraction time of the samples also is believed to have interfered with the profile of the compounds. The influence of this experimental condition can be seen by the distance along the PC2 of the samples extracted by the same fiber at different exposure times. For PA, PDMS and CAR/PDMS fibers, the 15 and 60 min times were positioned at the horizontal ends, while the other times were included in this interval (Figure 3), proving that the 60 min time was the equilibrium for maximum extraction of volatile compounds. In other words, the temperature range for PC2 loadings was more influenced by exposure times between 15 and 60 min.

According to the PCA of the in vivo data, the PA and CAR/PDMS fibers were at the vertical ends, since both showed divergences in the extracted constituents. An example of this occurrence was observed with the CAR/PDMS fiber due to the extracted monoterpenes, unlike with the PA fiber.

To extract a significant number of different compounds, the PA and CAR/PDMS fibers were selected for the continuation of the experiments in the in vitro sampling, as together they provided a better evaluation of the floral scent. In addition, extraction times of 15 and 60 min were also selected in the extraction of VOCs for in vitro samples. Considering the multivariate approach of the data, the choice of fibers and the exposure times mentioned together leads to an experimental condition that allows for data collection along with all spaces of data variance provided by the four fibers measured in this study.

\section{In vitro sampling of the flower scent of $X$. aromatica}

In most of the scientific articles ${ }^{13,16,27,28}$ in which the SPME technique is used, it is carried out in investigations with in vitro samples because of the facility in developing the entire analysis protocol in the laboratory. However, previous studies ${ }^{29,30}$ have reported that the volatile composition of plants that have undergone some types of disturbances differ significantly from the live or undamaged specimen in response to biotic and/or abiotic stress. Hence, the impact of $X$. aromatica scent collection was assessed by comparing the volatile profiles obtained in vivo and in vitro.

The optimal extraction temperature in experiments of this nature is dependent on the matrixes used. Considering the temperature employed during the in vivo experiments $\left(29.0 \pm 3.6{ }^{\circ} \mathrm{C}\right)$ as well as the effect of the temperature increase, the in vivo extraction was evaluated at 29.0 and $40 .{ }^{\circ} \mathrm{C}$ and at the exposure times of 15 and $60 \mathrm{~min}$ in the PCA.

The amounts of compounds obtained at 29.0 and $40.0{ }^{\circ} \mathrm{C}$ of extraction times of 15 and $60 \mathrm{~min}$ are shown 
(Figure 4) which indicated an increase in the extraction amounts over time leading to a greater number of VOCs being extracted at a temperature of $29.0^{\circ} \mathrm{C}$. The decrease in the number of VOCs at $40.0{ }^{\circ} \mathrm{C}$ may have occurred due to higher temperature coating headspace partition coefficients. ${ }^{31}$ Consequently, there was less diffusion of the compounds in the coatings which directly influenced the retention capacity.

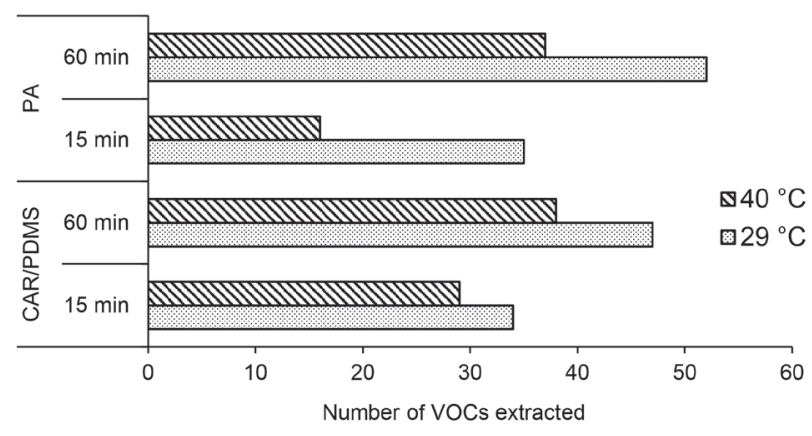

Figure 4. Effect of extraction temperature in vitro sampling of volatile compounds from $X$. aromatica flowers.

\section{PCA of the in vitro sampling}

To evaluate the temperature interference in the extraction of volatile compounds from the flowers of $X$. aromatica, a PCA was performed for in vitro samples of PA and CAR/PDMS fibers at selected extraction times of 15 and $60 \mathrm{~min}$, which was extended to the PCA of the in vivo extraction, as previously mentioned. Thus, the scores plot obtained for PC1 and PC2 explained $62.10 \%$ of data variance (Figure 5). In the same way for the in vivo experiments, the segregation of samples in two groups is clearly obtained along the PC1.

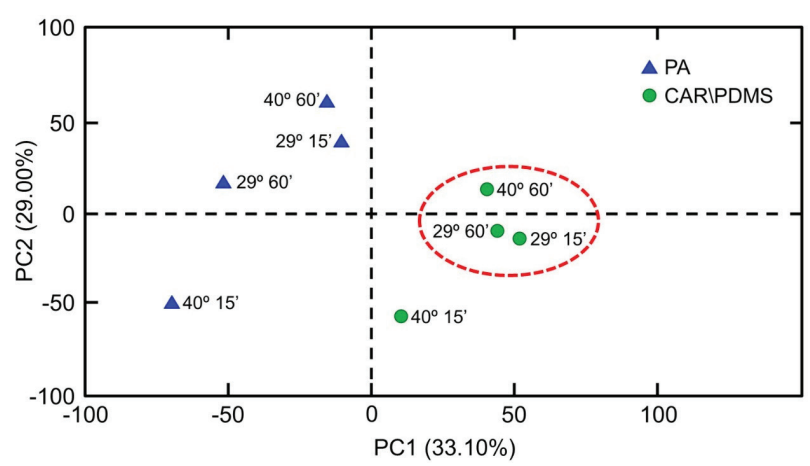

Figure 5. Scores plot of PCA for chromatograms obtained by evaluating the temperature from in vitro experiments.

As can easily be identified by the cluster highlighted (dashed line) in the scores plot shown in Figure 5 for the CAR/PDMS fiber, the variance of the data was small, except for the experiment performed at $15 \mathrm{~min}$ and $40{ }^{\circ} \mathrm{C}$ of exposure time and temperature, respectively. While for the PA fiber, the scores plot showed that the variance of the data was notably significant for the variables which also correlated with PC2.

Still, regarding the scores plot as with the case of PCA, the in vitro results obtained of significance in the sense that a simple and direct comparison against the data from Figure 4 may lead to erroneous conclusions. In Figure 4, the result is presented solely on quantitative data (number of detected and identified compounds), while on the other hand, the PCA analysis takes into account at the same time each signal and its respective intensities. This obviously denotes a quantitative influence on the analysis.

In vivo and in vitro composition of VOCs from $X$. aromatica

The HS-SPME optimized method (PA and CAR/PDMS fibers; $60 \mathrm{~min}$ and $29.0^{\circ} \mathrm{C}$ extraction time and temperature, respectively) availed a total of 77 VOCs of which 48 were reported for the first time in the literature as constituents of the volatile profile of $X$. aromatica flowers. Table 1 summarizes the identification of the peaks of the in vivo and in vitro sampling, their relative retention times (RRt), RI values obtained by using an HP-5 MS column and comparisons to RI values from the literature. ${ }^{18-20}$ Using in vivo and in vitro sampling, it was possible to extract 52 and 68 VOCs, respectively. Of these, nine (11.7\%) and twenty-five $(32.5 \%)$ were extracted exclusively by in vivo and in vitro sampling, respectively, while forty-three $(55.8 \%)$ were extracted by both (Figure S1, Supplementary Information (SI) section).

Of the forty-three compounds common to both analyses, twenty-four ((E)- $\beta$-ocimene (6), terpinolene (7), indole (15), $\alpha$-cubebene (16), $\alpha$-copaene (20), $\beta$-cubebene (22), $\beta$-elemene (23), trans-caryophyllene (24), aromadendrene (27), $\alpha$-humulene (30), 9-epi-(E)-caryophyllene (31), $\gamma$-muurolene (35), $\alpha$-amorphene (36), valencene (40), $\alpha$-muurolene (41), $(E, E)$ - $\alpha$-farnesene (42), $\delta$-cadinene (45), zonarene (46), $\alpha$-calacorene (50), spathulenol (52), 1 -epi-cubenol (60), $\alpha$-cadinol (65), pentadecan-2-one (70) and heptadecan-2-one (76)) were identified in previous studies in the leaves,,$^{3,5,7,16,32-36}$ flowers, ${ }^{5,16,37}$ fruits $^{16,27}$ and stems $^{32}$ of $X$. aromatica. It should be noted that spathulenol (52) has been reported in earlier research ${ }^{3,5,7,16,27,32-37}$ in different parts of $X$. aromatica and can be considered a chemotaxonomic marker of this genera. ${ }^{3,38}$

The difference in the extraction efficiency of the volatile constituents may be related to the sizes of the vials used in vivo $(250 \mathrm{~mL})$ and in vitro $(20 \mathrm{~mL})$, as shown in Figure 1. Note that the equilibrium is more rapidly established in vials with reduced headspace volumes. ${ }^{39}$ Thus, higher 
Table 1. Composition in vivo and in vitro sampling of the VOCs from the floral scent of X. aromatica by HS-SPME

\begin{tabular}{|c|c|c|c|c|c|c|c|c|}
\hline \multirow{3}{*}{ No. } & \multirow{3}{*}{$\mathrm{RRt} / \mathrm{min}$} & \multirow{3}{*}{$\mathrm{RI}^{\mathrm{a}}$} & \multirow{3}{*}{$\mathrm{RI}^{\mathrm{b}}$} & \multirow{3}{*}{ Compound $^{c}$} & \multicolumn{4}{|c|}{ Fiber } \\
\hline & & & & & \multicolumn{2}{|c|}{ PA } & \multicolumn{2}{|c|}{ CAR/PDMS } \\
\hline & & & & & In vivo & In vitro & In vivo & In vitro \\
\hline 1 & 7.46 & 987 & 990 & $\beta$-pinene ${ }^{17,18}$ & - & - & - & $x$ \\
\hline 2 & 7.69 & 997 & 1002 & myrcene $^{17,18}$ & - & $x$ & - & - \\
\hline 3 & 8.62 & 1026 & 1029 & $R$-limonene $\mathrm{d}^{\mathrm{d} 17,18}$ & - & - & - & $x$ \\
\hline 4 & 8.80 & 1032 & 1030 & sylvestrene $e^{17,18}$ & - & $x$ & - & - \\
\hline 5 & 8.91 & 1035 & 1037 & $(Z)-\beta$-ocimene ${ }^{17,18}$ & - & - & - & $x$ \\
\hline 6 & 9.36 & 1049 & 1050 & (E)- $\beta$-ocimene ${ }^{17,18}$ & - & $x$ & $x$ & $x$ \\
\hline 7 & 10.81 & 1093 & 1088 & terpinolene $\mathrm{e}^{17,18}$ & - & - & $x$ & $x$ \\
\hline 8 & 11.53 & 1115 & 1107 & 2-phenylethanol ${ }^{17,18}$ & - & $x$ & - & $x$ \\
\hline 9 & 12.04 & 1130 & 1132 & allo-ocimene $e^{17,18}$ & - & - & $x$ & $x$ \\
\hline 10 & 12.46 & 1143 & 1144 & neo-allo-ocimene $\mathrm{e}^{17,18}$ & - & - & $x$ & $x$ \\
\hline 11 & 15.44 & 1233 & 1229 & nerol $^{17,18}$ & - & $x$ & - & - \\
\hline 12 & 15.79 & 1244 & 1238 & citronellol $^{17,18}$ & - & $x$ & - & - \\
\hline 13 & 16.25 & 1258 & 1252 & geraniol $^{17,18}$ & - & $x$ & - & - \\
\hline 14 & 16.77 & 1274 & 1267 & geranial $^{17,18}$ & - & $x$ & - & - \\
\hline 15 & 17.65 & 1301 & 1291 & indole 17,18 & $x$ & $x$ & $x$ & $x$ \\
\hline 16 & 19.37 & 1353 & 1348 & $\alpha$-cubebene $\mathrm{e}^{17,18}$ & $x$ & $x$ & $x$ & $x$ \\
\hline 17 & 19.83 & 1367 & 1361 & neryl acetate $\mathrm{e}^{17,18}$ & - & $x$ & - & - \\
\hline 18 & 19.89 & 1368 & 1371 & cyclosativene $^{17,18}$ & - & - & - & $x$ \\
\hline 19 & 20.05 & 1373 & 1375 & $\alpha$-ylangene ${ }^{17,18}$ & - & $x$ & $x$ & $x$ \\
\hline 20 & 20.21 & 1378 & 1376 & $\alpha$-copaene $e^{17,18}$ & $x$ & $x$ & $x$ & $x$ \\
\hline 21 & 20.50 & 1387 & 1388 & $\beta$-bourbonene ${ }^{17,18}$ & $x$ & - & $x$ & - \\
\hline 22 & 20.67 & 1392 & 1388 & $\beta$-cubebene ${ }^{17,18}$ & - & - & $x$ & $x$ \\
\hline 23 & 20.72 & 1394 & 1390 & $\beta$-elemene ${ }^{\mathrm{d} 17,18}$ & $x$ & $x$ & - & $x$ \\
\hline 24 & 21.59 & 1422 & 1417 & trans-caryophyllene $\mathrm{d}^{\mathrm{d} 17,18}$ & $x$ & $x$ & $x$ & $x$ \\
\hline 25 & 21.89 & 1432 & 1432 & $\beta$-copaene $\mathrm{e}^{17,18}$ & $x$ & $x$ & $x$ & $x$ \\
\hline 26 & 22.10 & 1438 & 1433 & $\beta$-gurjunene ${ }^{17,18}$ & - & $x$ & - & - \\
\hline 27 & 22.38 & 1448 & 1441 & aromadendrene ${ }^{17,18}$ & $x$ & $x$ & - & - \\
\hline 28 & 22.43 & 1450 & 1450 & cis-muurola-3,5-diene ${ }^{17,18}$ & - & - & $x$ & $x$ \\
\hline 29 & 22.56 & 1454 & 1453 & trans-muurola-3,5-diene ${ }^{17,18}$ & $x$ & $x$ & $x$ & $x$ \\
\hline 30 & 22.66 & 1457 & 1454 & $\alpha$-humulene $e^{\mathrm{d} 17,18}$ & $x$ & $x$ & $x$ & $x$ \\
\hline 31 & 22.89 & 1465 & 1466 & 9-epi-(E)-caryophyllene ${ }^{17,18}$ & $x$ & $x$ & $x$ & $x$ \\
\hline 32 & 22.96 & 1467 & 1466 & cis-muurola-4(14),5-diene $\mathrm{e}^{17,18}$ & - & $x$ & - & - \\
\hline 33 & 23.12 & 1473 & 1472 & dauca-5,8-diene ${ }^{17,18}$ & - & - & $x$ & $x$ \\
\hline 34 & 23.28 & 1478 & 1476 & trans-cadina-1(6),4-diene $\mathrm{e}^{17,18}$ & $x$ & $x$ & $x$ & $x$ \\
\hline 35 & 23.39 & 1480 & 1479 & $\gamma$-muurolene $\mathrm{e}^{17,18}$ & $x$ & $x$ & $x$ & $x$ \\
\hline 36 & 23.50 & 1484 & 1484 & $\alpha$-amorphene $\mathrm{e}^{17,18}$ & $x$ & $x$ & $x$ & $x$ \\
\hline 37 & 23.84 & 1496 & 1493 & trans-muurola-4(14),5-diene ${ }^{17,18}$ & $x$ & $x$ & $x$ & $x$ \\
\hline 38 & 23.91 & 1499 & 1496 & tridecan-2-one $\mathrm{d}^{\mathrm{d} 17,18}$ & - & $x$ & - & - \\
\hline 39 & 23.93 & 1499 & 1495 & cis-cadina-1,4-diene $^{17,18}$ & $x$ & - & $x$ & $x$ \\
\hline 40 & 24.03 & 1502 & 1496 & valencene $\mathrm{e}^{17,18}$ & - & $x$ & $x$ & - \\
\hline 41 & 24.08 & 1505 & 1500 & $\alpha$-muurolene $e^{17,18}$ & $x$ & $x$ & $x$ & $x$ \\
\hline 42 & 24.30 & 1511 & 1505 & $(E, E)$ - $\alpha$-farnesene $e^{17,18}$ & - & $x$ & $x$ & $x$ \\
\hline 43 & 24.50 & 1518 & 1512 & $\delta$-amorphene $e^{17,18}$ & - & $x$ & $x$ & $x$ \\
\hline 44 & 24.58 & 1520 & 1513 & $\gamma$-cadinene $e^{17,18}$ & - & $x$ & - & $x$ \\
\hline 45 & 24.62 & 1523 & 1523 & $\delta$-cadinene ${ }^{17,18}$ & $x$ & $x$ & - & - \\
\hline 46 & 24.81 & 1529 & 1529 & zonarene $^{17,18}$ & $x$ & $x$ & $x$ & - \\
\hline 47 & 24.89 & 1531 & & n.i. ${ }^{\mathrm{e}}$ & $x$ & $x$ & $x$ & $x$ \\
\hline 48 & 25.06 & 1537 & 1534 & trans-cadina-1,4-diene ${ }^{17,18}$ & $x$ & $x$ & $x$ & $x$ \\
\hline 49 & 25.20 & 1542 & 1538 & $\alpha$-cadinene ${ }^{17,18}$ & - & $x$ & $x$ & $x$ \\
\hline 50 & 25.35 & 1546 & 1545 & $\alpha$-calacorene $e^{17,18}$ & $x$ & $x$ & $x$ & $x$ \\
\hline 51 & 26.24 & 1576 & & n.i..$^{e}$ & $x$ & - & - & - \\
\hline 52 & 26.32 & 1579 & 1578 & spathulenol $^{17,18}$ & $x$ & $x$ & $x$ & $x$ \\
\hline 53 & 26.60 & 1588 & 1587 & gleenol $^{17,18}$ & $x$ & - & $x$ & - \\
\hline
\end{tabular}


Table 1. Composition in vivo and in vitro sampling of the VOCs from the floral scent of X. aromatica by HS-SPME (cont.)

\begin{tabular}{|c|c|c|c|c|c|c|c|c|}
\hline \multirow{3}{*}{ No. } & \multirow{3}{*}{$\mathrm{RRt} / \mathrm{min}$} & \multirow{3}{*}{$\mathrm{RI}^{\mathrm{a}}$} & \multirow{3}{*}{$\mathrm{RI}^{\mathrm{b}}$} & \multirow{3}{*}{ Compound $^{c}$} & \multicolumn{4}{|c|}{ Fiber } \\
\hline & & & & & \multicolumn{2}{|c|}{$\mathrm{PA}$} & \multicolumn{2}{|c|}{ CAR/PDMS } \\
\hline & & & & & In vivo & In vitro & In vivo & In vitro \\
\hline 54 & 26.64 & 1590 & & cadina-1(10),6,8-triene $^{f 17,20}$ & - & - & $\times$ & $x$ \\
\hline 55 & 26.88 & 1598 & 1597 & tretadecan-2-one ${ }^{17,19}$ & - & $x$ & - & - \\
\hline 56 & 26.94 & 1600 & & $\alpha$-patchoulene $e^{\mathrm{g}} 17,20$ & - & - & - & $x$ \\
\hline 57 & 27.29 & 1613 & 1607 & $\beta$-oplopenone ${ }^{17,18}$ & $x$ & $x$ & - & - \\
\hline 58 & 27.58 & 1623 & & n.i..$^{e}$ & - & - & - & $x$ \\
\hline 59 & 27.66 & 1626 & 1623 & $\alpha$-corocalene $\mathrm{e}^{17,18}$ & - & - & $x$ & - \\
\hline 60 & 27.82 & 1632 & 1628 & 1-epi-cubenol ${ }^{17,18}$ & $x$ & $x$ & $x$ & $x$ \\
\hline 61 & 27.98 & 1638 & 1641 & allo-aromadendrene epoxide ${ }^{17,18}$ & $x$ & - & - & - \\
\hline 62 & 27.99 & 1638 & & n.i. ${ }^{\mathrm{e}}$ & - & - & $x$ & $x$ \\
\hline 63 & 28.08 & 1642 & 1641 & 1,7 -diepi- $\alpha$-cedrenal ${ }^{17,18}$ & $x$ & - & - & - \\
\hline 64 & 28.19 & 1646 & 1646 & $\alpha$-muurolol ${ }^{17,18}$ & $x$ & $x$ & $x$ & $x$ \\
\hline 65 & 28.57 & 1659 & 1654 & $\alpha$-cadinol ${ }^{17,18}$ & - & $x$ & $x$ & $x$ \\
\hline 66 & 28.69 & 1644 & & n.i. ${ }^{\mathrm{e}}$ & - & $x$ & - & - \\
\hline 67 & 28.96 & 1674 & 1668 & (6Z)-pentadecen-2-one ${ }^{17,18}$ & - & $x$ & - & - \\
\hline 68 & 29.13 & 1680 & 1676 & cadalene $\mathrm{e}^{17,18}$ & - & - & $x$ & $\times$ \\
\hline 69 & 29.46 & 1692 & 1686 & germacra-4(15),5,10(14)-trien-1- $\alpha$-ol ${ }^{17,18}$ & $x$ & - & - & - \\
\hline 70 & 29.72 & 1702 & 1697 & pentadecan-2-one $\mathrm{d}^{\mathrm{d} 17,18}$ & $x$ & $x$ & $x$ & $x$ \\
\hline 71 & 30.86 & 1744 & 1740 & oplopanone ${ }^{17,18}$ & $x$ & - & - & - \\
\hline 72 & 32.40 & 1800 & 1800 & hexadecan-2-one ${ }^{17,19}$ & - & $x$ & - & - \\
\hline 73 & 32.63 & 1810 & 1803 & 14-hydroxy- $\delta$-cadinene ${ }^{17,18}$ & $x$ & - & - & - \\
\hline 74 & 34.15 & 1871 & & (Z)-9,17-octadecadienal ${ }^{\text {h } 17,20}$ & - & $x$ & - & - \\
\hline 75 & 34.30 & 1877 & & n.i..$^{\mathrm{e}}$ & - & $x$ & - & - \\
\hline 76 & 34.98 & 1904 & 1902 & heptadecan-2-one $\mathrm{e}^{17,19}$ & $\times$ & $x$ & - & - \\
\hline 77 & 39.64 & 2100 & 2100 & $n$-heneicosane ${ }^{17,18}$ & - & $\times$ & - & - \\
\hline \multicolumn{5}{|c|}{ Total compounds identified per fiber } & 33 & 49 & 39 & 44 \\
\hline \multicolumn{9}{|c|}{ Classes of compounds from in vivo and in vitro sampling / \% } \\
\hline \multicolumn{4}{|c|}{ Monoterpenes } & \multicolumn{5}{|c|}{18.18} \\
\hline \multicolumn{4}{|c|}{ Alcohols } & \multicolumn{5}{|c|}{1.30} \\
\hline \multicolumn{4}{|c|}{ Aromatic heterocyclic } & \multicolumn{5}{|c|}{1.30} \\
\hline \multicolumn{4}{|c|}{ Sesquiterpenes } & \multicolumn{5}{|c|}{61.04} \\
\hline \multicolumn{4}{|c|}{ Hydrocarbons } & \multicolumn{5}{|c|}{1.30} \\
\hline \multicolumn{4}{|c|}{ Ketones aliphatic } & \multicolumn{5}{|c|}{7.79} \\
\hline \multicolumn{4}{|c|}{ Aldehyde aliphatic } & \multicolumn{5}{|c|}{1.30} \\
\hline \multicolumn{4}{|c|}{ Unknown } & \multicolumn{5}{|c|}{7.79} \\
\hline
\end{tabular}

sensitivity was obtained in the in vitro experiments, as the space above the sample was kept smaller when compared with the in vivo experiments.

Apart from the processes of emission, other conditions are related and directly influence the number of these VOCs. For example, abiotic factors (light, radiation, solar, temperature, soil composition, water and others), plant or flowers age, different species and/or cultivars. ${ }^{23}$ To maintain a homogeneous volatile profile, species with similar characteristics (aforementioned) should be sorted. Although in this study, different species of $X$. aromatica flowers were randomly sorted and used. Hence, this diversity of species could have influenced the VOCs reported here.
The composition of VOCs extracted in vitro was greater when compared with the in vivo procedure. This observation was attributed mainly to the nine new monoterpenes, (i.e., $\beta$-pinene (1), myrcene (2), $R$-limonene (3), sylvestrene (4), (Z)- $\beta$-ocimene (5), nerol (11), citronellol (12), geraniol (13) and geranial (14)) extracted. The same trend was observed for ketone hydrocarbons, where four new constituents (i.e., tridecan2-one (38), tretadecan-2-one (55), (6Z)-pentadecen-2one (67) and hexadecan-2-one (72)) were extracted. On the other hand, volatile constituents such as $\beta$-bourbonene (21), gleenol (53), $\alpha$-corocalene (59), allo-aromadendrene epoxide (61), 1,7-diepi- $\alpha$-cedrenal (63), germacra- 
4(15),5,10(14)-trien-1- $\alpha$-ol (69), oplopanone (71) and 14 -hydroxy- $\delta$-cadinene (73) were not observed in the in vitro sampling. This difference between the constituents extracted in vivo and in vitro may be connected with the fact that terpenoids easily undergo such reactions as oxidation, isomerization, cyclisation, or dehydrogenation reactions aided by the presence of enzymes or other chemicals. This is because VOCs are deprived of the protective compartmentalization provided in the plant matrix and are prone to oxidative damage or chemical transformations since these constituents under study are exposed to light, heat or air ${ }^{40}$ these conversion reactions may occur either when concentrated in the headspace or over time after the flower has been collected..$^{28}$

The volatile compounds cis-muurola-4(14),5-diene (32), $\gamma$-cadinene (44) and $n$-heneicosane (77) were selective to DVB/CAR/PDMS and PDMS coatings in the in vivo procedure. Nevertheless, the combination of fiber optimization with the use of smaller vials made it possible to extract them even by using a different CAR/PDMS and PA fibers in the in vitro sampling, which demonstrates greater extraction efficiency.

In comparison with the previous study, ${ }^{16}$ our analyses confirmed the importance of the extraction time and fiber selection for the VOCs extraction. Andrade et al. ${ }^{16}$ identified 13 compounds in X. aromatica occurring in Northern Brazil using CAR/PDMS fiber and extraction time of $15 \mathrm{~min}$. Similarly, this study identified 26 and 38 VOCs from extraction times of 15 and $60 \mathrm{~min}$, respectively using the same fiber but from the West-Central region of the country.

In the current paper, sesquiterpenes represent $61.04 \%$ of the identified volatile constituents of $X$. aromatica flowers. Comparing the data reported of other extraction techniques, such as hydrodistillation ${ }^{5}$ and dynamic headspace, ${ }^{37}$ sesquiterpenes were also found to be the dominant volatile compounds in flowers. The above realization corroborates with the findings reported in this study.

Most studies ${ }^{3,7,16,27}$ associated with the investigation of the volatile profile of the genus Xylopia have reported that its constituents are predominantly monoterpenes and sesquiterpenes. This same behavior is observed in our work, where both classes represent $79.22 \%$ of the total VOCs extracted.

The fact that the floral scent of $X$. aromatica flowers are mostly composed of terpenoids makes it the ideal species with great potential for exploration in the pharmaceutical, food and cosmetics industries, as these secondary metabolites are targets of several investigations in search of medicines, flavor enhancers and fragrances. ${ }^{41}$

\section{Conclusions}

In conclusion, this study provides the first and most comprehensive report of the volatile composition from the flowers of $X$. aromatica via in vivo and in vitro sampling. The use of HS-SPME and GC-MS techniques was efficient for the extraction and identification of the VOCs. A total of 77 VOCs was extracted from the floral scent, with 52 and 68 from in vivo and in vitro sampling, respectively, of which 48 were reported for the first time in the literature as volatile constituents from $X$. aromatica flowers. The PCA data was important to identify the most promising conditions of the experiments that led to the identification of the maximum number of VOCs. These conditions were the use of PA and CAR/PDMS fibers at as well as a $60 \mathrm{~min}$ extraction time and $29{ }^{\circ} \mathrm{C}$ temperature.

In addition, our study further revealed that there are volatile compositional scent differences between in vivo and in vitro sampling. Among the different classes of constituents identified, monoterpenes were the main ones responsible for such diversity.

\section{Supplementary Information}

Supplementary data are available free of charge at http://jbcs.sbq.org.br as a PDF file.

\section{Acknowledgments}

The authors would like to thank the Brazilian National Council for Scientific and Technological Development (grant number 422513/2016-4) for supporting this work. We also thank Dr Núbia Alves M. T. Gomides for the authentication of the vegetal material. This study was financed in part by the Coordenação de Aperfeiçoamento de Pessoal de Nível Superior Brazil (CAPES), finance code 001 .

\section{Author Contributions}

João G. M. Junqueira and Michelle N. G. do Nascimento were responsible for the conceptualization, methodology, validation, investigation, writing of original draft, review, editing and visualization; Lucas G. da Costa performed the formal analysis and visualization; Lincoln L. Romualdo was responsible for the conceptualization, methodology, resources, supervision, writing review and editing; Francisco W. B. de Aquino was responsible for the methodology, formal analysis, data curation, visualization, writing review and editing; Mustapha N. Abubakar carried out the writing review and editing; Ana P. Terezan and Gustavo 
O. S. Cunha were responsible for the conceptualization, methodology, writing review and editing; Vanessa G. P. Severino performed the conceptualization, resources, supervision, project administration, funding acquisition and writing review and editing.

\section{References}

1. Leboeuf, M.; Cavé, A.; Bhaumik, P. K.; Mukherjee, B.; Mukherjee, R.; Phytochemistry 1982, 21, 2783.

2. Moreira, I. C.; Roque, N. F.; Vilegas, W.; Zalewski, C. A.; Lago, J. H. G.; Funasaki, M.; Chem. Biodiversity 2013, 10, 1921.

3. Maia, J. G. S.; Andrade, E. H. A.; da Silva, A. C. M.; Oliveira, J.; Carreira, L. M. M.; Araújo, J. S.; Flavour Fragrance J. 2005, $20,474$.

4. di Stasi, L. C.; Himura-Lima, C. A.; Plantas Medicinais na Amazônia e na Mata Atlântica, $2^{\text {nd }}$ ed.; UNESP: São Paulo, 2003, p. 604.

5. Nascimento, M. N. G.; Junqueira, J. G. M.; Terezan, A. P.; Severino, R. P.; Silva, T. S.; Martins, C. H. G.; Severino, V. G. P.; Rev. Virtual Quim. 2018, 10, 1578.

6. Fournier, G.; Leboeuf, M.; Cavé, A.; J. Essent. Oil Res. 1999 , $11,131$.

7. Lago, J. H. G.; de Ávila, P.; Moreno, P. R. H.; Limberger, R. P.; Apel, M. A.; Henriques, A. T.; Biochem. Syst. Ecol. 2003, 31, 669.

8. Estrada, O.; González, L.; Mijares, M.; Fernández, Á.; Ruiz, M.; Taylor, P.; Planta Med. 2013, 79, PF10.

9. Vergara, J. L. T.; Hernández, J. E.; Carvajal, G. A. V.; Ramos, J. D.; Rev. Cubana Farm. 2006, 40, 2.

10. Garavito, G.; Rincón, J.; Arteaga, L.; Hata, Y.; Bourdy, G.; Gimenez, A.; Pinzón, R.; Deharo, E.; J. Ethnopharmacol. 2006, 107,460 .

11. Oliveira, V. B.; Ferreira, A. V. M.; Oliveira, M. C.; Teixeira, M. M.; Brandão, M. G. L.; Food Res. Int. 2014, 62, 541.

12. Belliardo, F.; Bicchi, C.; Cordero, C.; Liberto, E.; Rubiolo, P.; Sgorbini, B.; J. Chromatogr. Sci. 2006, 44, 416.

13. Farag, M. A.; El-Kersh, D. M.; Rasheed, D. M.; Heiss, A. G.; Ind. Crops Prod. 2017, 108, 564.

14. Spietelun, A.; Marcinkowski, Ł.; de la Guardia, M.; Namieśnik, J.; J. Chromatogr. A 2013, 1321, 1.

15. Zhu, F.; Xu, J.; Ke, Y.; Huang, S.; Zeng, F.; Tiangang, L.; Ouyang, G.; Anal. Chim. Acta 2013, 794, 1.

16. Andrade, E. H. A.; da Silva, A. C. M.; Carreira, L. M. M.; Oliveira, J.; Maia, J. G. S.; J. Essent. Oil-Bear. Plants 2004, 7, 151.

17. National Institute of Standards and Technology (NIST); NIST/EPA/NIH MS/MS Mass Spectral Library 2017; Wiley, Gaithersburg, 2017.
18. Adams, R. P.; Identification of Essential Oil Components by Gas Chromatography/Mass Spectrometry, $4^{\text {th }}$ ed.; Allured Publishing Corporation: Illinois, USA, 2007.

19. Rostad, C. E.; Pereira, W. E.; J. High Resolut. Chromatogr. 1986, 9, 328.

20. National Center for Biotechnology Information (NCBI); PubChem Compound Database, available at https://www.ncbi. nlm.nih.gov/pccompound, accessed in January 2021.

21. Pirouette, version 4.5; Infometrix, Bothell, USA, 2011.

22. Musteata, F. M.; Pawliszyn, J.; J. Biochem. Biophys. Methods 2007, 70, 181.

23. Ouyang, G.; Vuckovic, D.; Pawliszyn, J.; Chem. Rev. 2011, $111,2784$.

24. Pawliszyn, J.; Aust. J. Chem. 2003, 56, 155.

25. Wold, S.; Esbensen, K.; Geladi, P.; Chemom. Intell. Lab. Syst. 1987, 2, 37.

26. Santos, P. M.; Pereira-Filho, E. R.; Anal. Methods 2013, 5, 3669.

27. Stashenko, E. E.; Jaramillo, B. E.; Martínez, J. R.; J. Chromatogr. A 2004, 1025, 105.

28. Souza-Silva, É. A.; Saboia, G.; Jorge, N. C.; Hoffmann, C.; dos Santos-Isaias, R. M.; Soares, G. L. G.; Zini, C. A.; Talanta 2017, 175, 9.

29. Giorgi, A.; Manzo, A.; Nanayakkara, N. N. M. C.; Giupponi, L.; Cocucci, M.; Panseri, S.; Nat. Prod. Res. 2015, 29, 1695.

30. Vereen, D. A.; McCall, J. P.; Butcher, D. J.; Microchem. J. 2000, $65,269$.

31. Zhang, Z.; Yang, M. J.; Pawliszyn, J.; Anal. Chem. 1994, 66, 844.

32. Fournier, G.; Hadjiakhoondi, A.; Charles, B.; Fourniat, J.; Leboeuf, M.; Cavé, A.; Planta Med. 1994, 60, 283.

33. Jaramillo-Colorado, B. E.; Stashenko, E. E.; Winterhalter, P.; J. Essent. Oil Res. 2020, 32, 12.

34. Peres, M.; Costa, G. C. S.; dos Reis, L. E. L.; da Silva, L. D.; Peixoto, M. F.; Alves, C. C. F.; Forim, M. R.; Quintela, E. D.; Araújo, W. L.; Cazal, C. M.; J. Pest Sci. 2020, 93, 807.

35. Pino, J. A.; Bello, A.; Urquiola, A.; Garcia, S.; Rosado, A.; J. Essent. Oil Res. 2000, 12, 751.

36. Alcântra, J. M.; de Lucena, J. M. V. M.; Facanali, R.; Marques, M. O. M.; da Paz Lima, M.; Nat. Prod. Commun. 2017, 12, 619.

37. Jürgens, A.; Webber, A. C.; Gottsberger, G.; Phytochemistry 2000, 55, 551.

38. Maia, J. G. S.; Andrade, E. H. A.; Carreira, L. M. M.; Oliveira, J.; Araújo, J. S.; Flavour Fragrance J. 2005, 20, 478.

39. Yang, X.; Peppard, T.; J. Agric. Food Chem. 1994, 42, 1925.

40. Turek, C.; Stintzing, F. C.; Compr. Rev. Food Sci. Food Saf. 2013, 12, 40 .

41. Caputi, L.; Aprea, E.; Recent Pat. Food, Nutr. Agric. 2012, 3 , 9. 